\title{
Development of a lateral flow recombinase polymerase amplification assay for rapid and visual detection of Cryptococcus neoformans/C. gattii in cerebral spinal fluid
}

\author{
Qinglin Ma ${ }^{1,2}$, Jilong Yao ${ }^{1}$, Shixin Yuan ${ }^{1}$, Houming $\mathrm{Liu}^{2}$, Ning Wei ${ }^{3^{*}}$, Jianming Zhang ${ }^{1 *}$ and Wanshui Shan ${ }^{2^{*}}$
}

\begin{abstract}
Background: For definitive diagnosis of cryptococcal meningitis, Cryptococcus neoformans and/or C. gattii must be identified within cerebral spinal fluid from the patients. The traditional methods for detecting Cryptococcus spp. such as India ink staining and culture are not ideal. Although sensitive and specific enough, detection of cryptococcal antigen polysaccharide has a high dose hook effect. Therefore, the aim of this study was to introduce a new rapid and simple detection method of Cryptococcus neoformans and C. gattii in cerebral spinal fluid.

Methods: The lateral flow strips combined with recombinase polymerase amplification (LF-RPA) assay was constructed to detect the specific DNA sequences of $C$. neoformans and C. gattii. The detection limit was evaluated using serial dilutions of C. neoformans and C. gattii genomic DNA. The specificity was assessed by excessive amount of other pathogens genomic DNA. The optimal detection time and amplification temperature were also analyzed. The diagnostic parameters were first calculated using 114 clinical specimens and then compared with that of other diagnostic method. A brief analysis and comparison of different DNA extraction methods was discussed, too.

Results: The LF-RPA assay could detect $0.64 \mathrm{pg}$ of genomic DNA of C. neoformans per reaction within 10 min and was highly specific for Cryptococcus spp.. The system could work well at a wide range of temperature from 25 to $45^{\circ} \mathrm{C}$. The overall sensitivity and specificity were 95.2 and $95.8 \%$ respectively. As amplification template for LF-RPA assay, both cell lysates and genomic DNA produce similar experimental results.

Conclusions: The LF-RPA system described here is shown to be a sensitive and specific method for the visible, rapid, and accurate detection of Cryptococcus spp. in cerebral spinal fluid and might be useful for clinical preliminary screening of cryptococcal meningitis.
\end{abstract}

Keywords: Cryptococcus neoformans, Cryptococcus gattii, Recombinase polymerase amplification, Lateral flow strips, Cerebral spinal fluid, Visual detection

\footnotetext{
*Correspondence: szmch2004@hotmail.com; szmch_zhang@aliyun.com; wanshui_shan@126.com

${ }^{3}$ Personnel Section, Shenzhen Maternity and Child Healthcare Hospital, Southern Medical University, No.2004 Hongli Road, Shenzhen 518028, Guangdong, China

'Institute of Maternity and Child Medical Research, Shenzhen Maternity and Child Healthcare Hospital, Southern Medical University, No.2004 Hongli Road, Shenzhen 518028, Guangdong, China

${ }^{2}$ Clinical Laboratory, Shenzhen Third People's Hospital, No.29 Bulan Road, Shenzhen 518112, Guangdong, China
}

(c) The Author(s). 2019 Open Access This article is distributed under the terms of the Creative Commons Attribution 4.0 International License (http://creativecommons.org/licenses/by/4.0/), which permits unrestricted use, distribution, and reproduction in any medium, provided you give appropriate credit to the original author(s) and the source, provide a link to the Creative Commons license, and indicate if changes were made. The Creative Commons Public Domain Dedication waiver (http://creativecommons.org/publicdomain/zero/1.0/) applies to the data made available in this article, unless otherwise stated. 
Early diagnosis and treatment of cryptococcosis reduces mortality. Lumbar puncture, also known as spinal tap, and cerebral spinal fluid (CSF) analysis should be performed in patients with suspected CM $[3,6]$. For a definitive diagnosis of CM, Cryptococcus spp. must be identified within CSF from the patients $[2,3,7]$. India ink staining and culture are the traditional important methods for rapid detection of Cryptococcus spp. [6]. The sensitivity of India ink staining of the CSF is up to $70-90 \%$, which tends to be lower in HIV-negative patients, but this value is dependent on both the fungal burden and operator $[2-4,8,9]$. The definitive diagnosis of CM relies on culture on standard Sabouraud dextrose agar (SDA) or using routine and automated culture systems inoculated with CSF incubated at $30^{\circ} \mathrm{C}[4,10]$. However, culture may be negative if exposure to antifungal therapy or in non-HIV CM and might need longer incubation periods up to several weeks [8]. Serological diagnosis of CM, such as latex agglutination, enzymelinked immunosorbent assays and lateral flow assay, relies usually on specific monoclonal antibodies to detect cryptococcal antigen polysaccharide ( $\mathrm{CrAg})$. Although detection of $\mathrm{CrAg}$ has demonstrated good sensitivity and specificity [11-15], extremely high concentrations of $\mathrm{CrAg}$ can yield negative test results in extreme instances, known as high dose hook effect.

Recently, recombinase polymerase amplification (RPA), an isothermal in vitro nucleic acid amplification technique, appeared as a novel molecular technology for simple, robust (less sensitive to inhibitors), rapid, reliable, and low-resource diagnostics [16-19]. At present, RPA combined with lateral flow strips (LF-RPA assay) has been successfully used for the rapid and visual detection of several pathogens including parasites, viruses, and bacteria [18-21]. In this study, we have assessed the performance of LF-RPA assay for detecting genomic DNA of C. neoformans and C. gattii in clinical CSF samples from patients.

\section{Methods}

\section{Primer and probe design}

To establish a nucleic acid-based detection method, the starting point is to identify the research target [22]. The internal transcribed spacer (ITS) sequences of ribosomal RNA gene are highly variable and useful for species differentiation [23-25]. A total of 139 available ITS sequences of $C$. neoformans or $C$. gattii were downloaded from the GenBank ${ }^{\circledast}$ database (https://www.ncbi.nlm.nih.gov/genbank/). DNAMAN software (Lynnon LLC., California, USA) was used to obtain the consensus sequence by multiple sequence alignment. Primer and probe for LF-RPA assay were designed based on the consensus sequence according to the guidelines of TwistAmp ${ }^{\bullet}$ DNA amplification kit (TwistDx Ltd., UK). The optimal primer-probe combination was obtained by screening via the basic local alignment search tool BLASTN (https://blast.ncbi.nlm.nih.gov/Blast.cgi) and actual testing. All oligonucleotides were synthesized by Beijing AuGCT DNA-SYN Biotechnology Co. Ltd. (Beijing, China) and shown in Table 1.

\section{Clinical specimens and strains}

To evaluate the diagnostic validity of our LF-RPA method, 114 CSF specimens (one sample from one patient with similar clinical symptoms to CM) were collected from Shenzhen Third People's Hospital. At the time of the experiment, researchers did not know the pathogenic biological status of the above-mentioned samples. The results of LF-RPA assay and "CrAg Lateral Flow Assay" were compared to that of culture and/or India ink staining. Diagnostic parameters such as the overall specificity and sensitivity were evaluated using the free "diagnostic test evaluation calculator" (https://www.medcalc.org/calc/diagnostic_test.php) and expressed as percentages in Table 3.

India ink staining and "CrAg Lateral Flow Assay" were performed using the "Cryptococcus neoformans stain kit" (BA4042, Baso diagnostics, Inc. Zhuhai, China) and "Cryptococcal Antigen Lateral Flow Assay Kit" (CR2003, IMMY, Inc. Oklahoma, USA), respectively, according to the product instructions.

Culture was conducted at $25^{\circ} \mathrm{C}$ and $37^{\circ} \mathrm{C}$ for $2-4$ weeks using the "BD BACTEC ${ }^{\mathrm{Tm}}$ FX Blood Culture System" (BD Diagnostics, New Jersey, USA) and standard Sabouraud dextrose agar (Oxoid Limited, Hampshire, UK) [6, 10]. The positive cultures were screened for Cryptococcus spp. using the "MALDI Biotyper Systems" (Bruker Daltonik $\mathrm{GmbH}$, Bremen, Germany).

In addition, clinical isolates were collected from Shenzhen Third People's Hospital and the standard strains were bought from the American Type Culture Collection (ATCC, Manassas, Virginia, USA).

Table 1 Oligonucleotide primers and probe for LF-RPA assay

\begin{tabular}{ll}
\hline Name & Sequence $\left(5^{\prime} \rightarrow 3^{\prime}\right)$ \\
\hline CM ITS P4 & FITC-TACACAAACTTCTAAATGTAATGAATGTAATC(H)TATTATAACA ATAATAAA-P \\
CM ITS F4 & TGAACTGTTTATGTGCTTCGGCACGTTTAC \\
CM ITS R4 & Biotin-TCGATGTGGAAGCCAAGAGATCCGTTGTT \\
\hline
\end{tabular}

CM: cryptococcal meningitis; ITS: internal transcribed spacer of ribosomal RNA gene; F: forward primer; R: reverse primer; P: probe; FITC: fluorescein isothiocyanate; $\mathrm{H}$ : tetrahydrofuran spacer; $\mathrm{P}: 3^{\prime}$ phosphate to block elongation. 


\section{DNA extraction}

DNA extraction was conducted using glass beads (CapitalBio, Beijing, China) and boiling method as earlier reported with a little revision [26-28]. Briefly, a bit of sediments of CSF after centrifugation or fresh colonies were suspended in $50 \mu \mathrm{l}$ of $1 \times$ TE buffer $(10 \mathrm{mM}$ Tris-HCl, $1 \mathrm{mM}$ EDTA, $\mathrm{pH}$ 8.0) within an extraction tube and incubated at $95^{\circ} \mathrm{C}$ in a boiling water-bath for $5 \mathrm{~min}$. Then the total DNA was isolated by vortexing at maximum speed in an Extractor $^{\mathrm{Tx}}$ 36 (CapitalBio) for $5 \mathrm{~min}$. After centrifuged at $10000 \mathrm{~g}$ for $5 \mathrm{~min}$, the supernatant of the lysate containing gemonic DNA was separated for follow-up tests. This is "glass beads method" for sample cell lysate.

In order to meet the special needs of Fig. 4, we have further purified the supernatant of the lysate with "TIANamp Yeast DNA Kit" (TIANGEN Biotech, Beijing, China) starting from step 7 of the operating manual. This is "spin columns method" for DNA extraction.

DNA concentrations were accurately measured using the "Qubit 3 Fluorometer" (Q33216, Thermo Fisher Scientific, Wilmington, USA). All genomic DNA and sample lysate were kept in $-80^{\circ} \mathrm{C}$ to preserve, and avoid repeated freeze-thaw cycles.

\section{RPA assay}

RPA assay was carried out with $5 \mu$ of template according to the operating manual of "TwistAmp nfo kit" (TwistDx Ltd., UK) and the protocol previously described [20]. The "thermal cycler instrument" (HybriBio Ltd., Guangdong, China) was used to perform the reaction at $39^{\circ} \mathrm{C}$ for half an hour. Heated lids should be switched off before start. After the first 4 min of incubation, the reaction tubes were vortexed and spun again to improve the amplification efficiency.

For visual analysis with Milenia ${ }^{\circ}$ Genline Hybridetect1 strips (Milenia Biotec $\mathrm{GmbH}$, Germany), amplification product was diluted 1/10 with HybriDetect assay buffer inside a class II biosafety cabinet in product analysis room. Dipsticks were directly dipped into $50 \mu \mathrm{l}$ of diluents at room temperature and the visual result should be observed within $5 \mathrm{~min}$. If only the control band appears, it is considered to be negative result. If both the test and control bands display simultaneously, it is a positive result. If the control band is not visible after the incubation period, the result is invalid. The test must be repeated with a new dipstick. A piece of A4 paper was used to paste these dried dipsticks and then scanned by HP brother scanner (MFC-8535DN, Guangzhou, China).

\section{Assessment of LF-RPA performance}

For evaluation of the detection limit (the lowest quantity of template for positive result), dilutions of genomic DNA of C. neoformans var. grubii H99 (ATCC 208821) to $12.8 \mathrm{pg}, 1.28 \mathrm{pg}, 0.64 \mathrm{pg}, 0.32 \mathrm{pg}, 0.16 \mathrm{pg}$ and $0.128 \mathrm{pg}$ per $\mu \mathrm{l}$ was prepared in nuclease-free water and $1 \mu \mathrm{l}$ was used each reaction. LF-RPA assay was carried out in 5 replicates for each concentration gradient. The tests were repeated three times under the same conditions. One example of the results was presented in Fig. 1 and Fig. 4a.

To analyze the specificity of LF-RPA assay, at least 20 ng genomic DNA extracted from several pathogenic microorganisms which names were shown in Fig. 2 and Fig. 4b were used as templates each reaction.

The optimal amplification time was measured at $39^{\circ} \mathrm{C}$ and terminated at different incubation time points ranging from 0 to $40 \mathrm{~min}$ by immediately placing on ice and diluting with HybriDetect assay buffer.

The optimal incubation temperature of RPA reaction was determined at $4,10,15,20,25,30,35,40,45$ and $50{ }^{\circ} \mathrm{C}$, respectively.

\section{Results}

\section{Screening of optimal primer-probe combination}

Four candidate primer-probe combinations were screened for the best performance under the same conditions. Primer-probe combination that produced clearly visible bands fastest and had no cross-reactions with other pathogens was chosen for subsequent evaluations. The final sequences of primers and probe are listed in Table 1.

\section{Detection limit}

The detection threshold of LF-RPA assay was measured using serial dilutions of genomic DNA of $C$. neoformans var. grubii H99 (ATCC 208821) and C. gattii (ATCC MYA-4093). Five repetitive samples were analyzed for each concentration gradient (Table 2 \& Fig. 1). One example of the results of three repeated experiments is shown in Fig. 1. Clear test and control bands appeared on each strip with greater than or equal to $0.64 \mathrm{pg}$ of genomic DNA, while partial faint test bands or only control bands on other dipsticks (Fig. 1). Comprehensive five results per concentration gradient of three repeated experiments suggested that the LF-RPA assay could detect as low as $0.64 \mathrm{pg}$ of genomic DNA of $C$. neoformans per reaction, and $1.016 \mathrm{pg}$ of $C$. gattii.

\section{Cross-reactivity analysis}

To evaluate the detection specificity of the established LF-RPA assay, cross-reactions were performed with excessive amount of genomic DNA from a variety of different pathogens as templates. As shown in Fig. 2, only the Cryptococcus spp. dipsticks including C. neoformans and C. gattii displayed a solid positive test band, while no signals were observed on the other strips even other fungi's DNA as template. The results indicated that the primer-probe combination designed for the LF-RPA reactions was highly specific to its corresponding targets. 

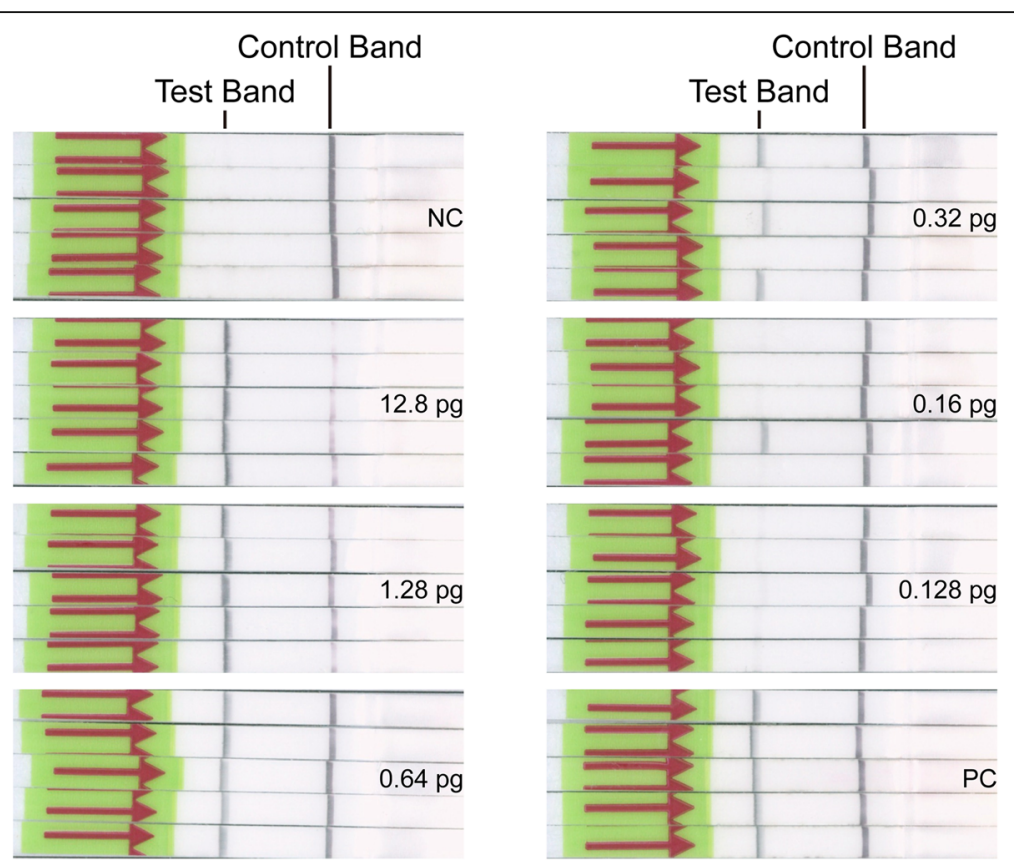

Fig. 1 Evaluation of the detection threshold. Different quantity of genomic DNA of C. neoformans var. grubii H99 (ATCC 208821), shown on the right side, was used as templates. The LF-RPA assay could detect as low as $0.64 \mathrm{pg}$ of genomic DNA of $C$. neoformans per test. pg: picogram; NC: negative control; PC: positive control

It's also suggested that the described LF-RPA assay was able to detect several different types of Cryptococcus strains, whether the clinical isolates or standard strains.

\section{Optimal amplification time and temperature}

To determine the optimal amplification time and temperature, the strips were incubated for $5 \mathrm{~min}$ at room temperature as earlier literatures reported $[20,29,30]$ and 0.64 pg of genomic DNA of C. neoformans var. grubii H99 (ATCC 208821) was used as template. As the results shown in Fig. 3a, a clear test band could be observed and became more solid as time extended to $10 \mathrm{~min}$ or more. It means that the amplification time is at least 10 min for effective observation. The optimal amplification temperature for LF-RPA reactions was determined by using different temperature settings. As we can see in Fig. 3b, test bands clearly appeared on the strips over a wide range of temperature from 25 to $45^{\circ} \mathrm{C}$ as previous study $[20,29]$, suggesting that the amplification reaction of LF-RPA assay is not sensitive to temperature gradients within a certain range.

\section{Analysis of clinical specimens}

In order to determine the diagnostic applicability, the LF-RPA assay and "CrAg Lateral Flow Assay" were compared to the gold standard diagnoses of cryptococcal meningitis (culture and/or India ink staining). These studies contained a mix of both prospective and retrospective specimens. A summary of the data collected was included in Table 3. Of the 72 negative specimens, 69 yielded negative results, and 40 out of the 42 positive samples showed positive results. The performance of " $\mathrm{CrAg}$ Lateral Flow Assay" was identical with that described in the kit instructions. The sensitivity and specificity of LF-RPA assay and "CrAg Lateral Flow Assay" were 95.2\% (95\% CI: $83.84-99.42 \%$ ) vs 100\% (95\% CI: $91.59-100 \%$ ) and $95.8 \%$ (95\% CI: $88.30-99.13 \%)$ vs $100 \%$ (95\% CI: 95.01-100\%), respectively.

\section{Comparison of different DNA extraction methods}

All the templates used in the above experiments were obtained by means of "glass beads method". Strictly speaking, the "glass beads method" only gets cell lysates instead of the real genomic DNA. To determine whether the cell lysates affect the reaction efficiency of LF-RPA assay, we have further purified the cell lysates using "TIANamp Yeast DNA Kit". This is "spin columns method" for genomic DNA extraction. Then, we used the DNA as templates for the similar experiments above-mentioned. As shown in Fig. 4, the detection limit of LF-RPA assay is also $0.64 \mathrm{pg}$ of genomic DNA per reaction and it could only detect genomic DNA of $C$. neoformans and $C$. gattii but not other pathogens. It's indicating that the above-mentioned different DNA extraction methods do not obviously affect the reaction efficiency of LF-RPA assay. 

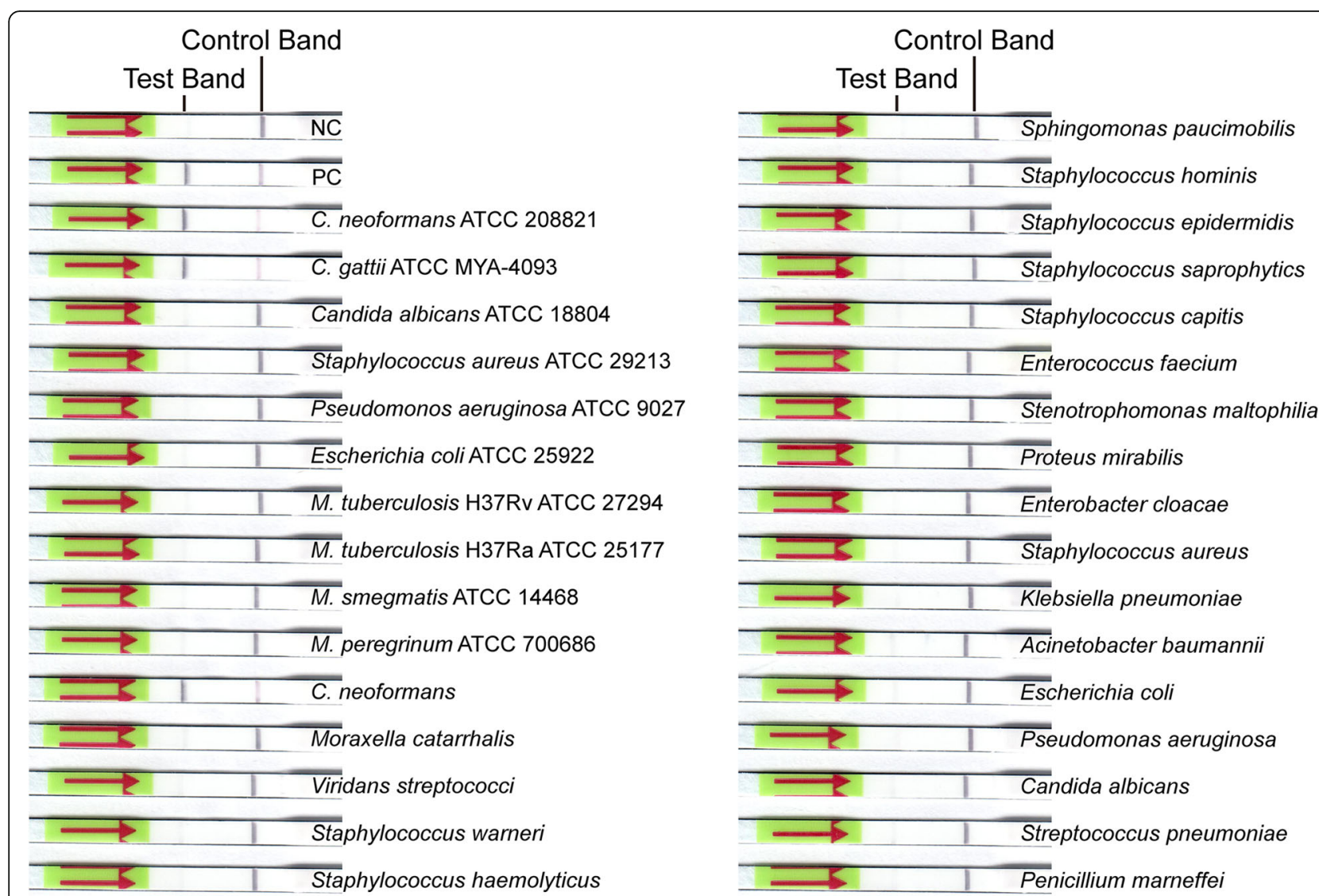

Fig. 2 Cross-reactivity analysis. Excessive amount of genomic DNA from a variety of different pathogens including bacteria and fungi was used as templates. Cross-reaction with any other pathogens was not detected. NC: negative control; PC: positive control

\section{Discussion}

At present, there is no widely used method for detecting Cryptococcus spp. based on nucleic acid amplification. Now we have described a new method, lateral flow recombinase polymerase amplification assay, to detect genomic DNA of Cryptococcus spp. and measured its several diagnostic parameters. The detection limit of LF-RPA assay is slightly higher than that of "CrAg Lateral Flow Assay". It is $0.64 \mathrm{pg}$ of $C$. neoformans genome (approximately equal to 30 copies) per reaction and enough to detect Cryptococcus spp. in most natural infection (the total length of $C$. neoformans var. grubii $\mathrm{H} 99$ genome is about $18.9161 \mathrm{Mbp}$ ) (https://www.ncbi.nlm.nih.gov/ genome/61?genome_assembly_id=52487). Besides, our
LF-RPA method was highly specific for Cryptococcus spp. and had no cross-reactivity with other pathogens.

Other advantages of the system were the shorter detection time and the wider range of amplification temperature. The detection time mainly includes template preparation time, RPA amplification time, and strips incubation time. Results described here indicate that the "glass beads method", taking about $15 \mathrm{~min}$, is sufficient to meet the needs of LF-RPA assay. That is to say, the template preparation time is about 15 min. Results shown in Fig. 3a suggest that the RPA amplification time is $10 \mathrm{~min}$ or more. Considering the requirements of detection rapidity, sensitivity and efficiency, $15 \mathrm{~min}$ is really enough for target amplification [20, 25, 29]. Several earlier reports and our

Table 2 Calculated the detection limit of LF-RPA assay

\begin{tabular}{|c|c|c|c|c|c|c|c|c|}
\hline DNA amount (pg/reaction) & NC & 12.8 & 1.28 & 0.64 & 0.32 & 0.16 & 0.128 & PC \\
\hline C. neoformans & $0 / 5^{\mathrm{a}}$ & $5 / 5^{\mathrm{a}}$ & $5 / 5^{\mathrm{a}}$ & $5 / 5^{\mathrm{a}}$ & $3 / 5^{a}$ & $1 / 5^{\mathrm{a}}$ & $0 / 5^{\mathrm{a}}$ & $5 / 5^{\mathrm{a}}$ \\
\hline DNA amount (pg/reaction) & NC & 20.32 & 2.032 & 1.016 & 0.508 & 0.254 & 0.2032 & PC \\
\hline C. gattii & $0 / 5^{a}$ & $5 / 5^{a}$ & $5 / 5^{a}$ & $5 / 5^{a}$ & $4 / 5^{a}$ & $1 / 5^{a}$ & $0 / 5^{a}$ & $5 / 5^{a}$ \\
\hline
\end{tabular}

${ }^{\mathrm{a}}$ The number of positive samples/the total number of samples tested by LF-RPA assay. NC: negative control; PC: positive control. 

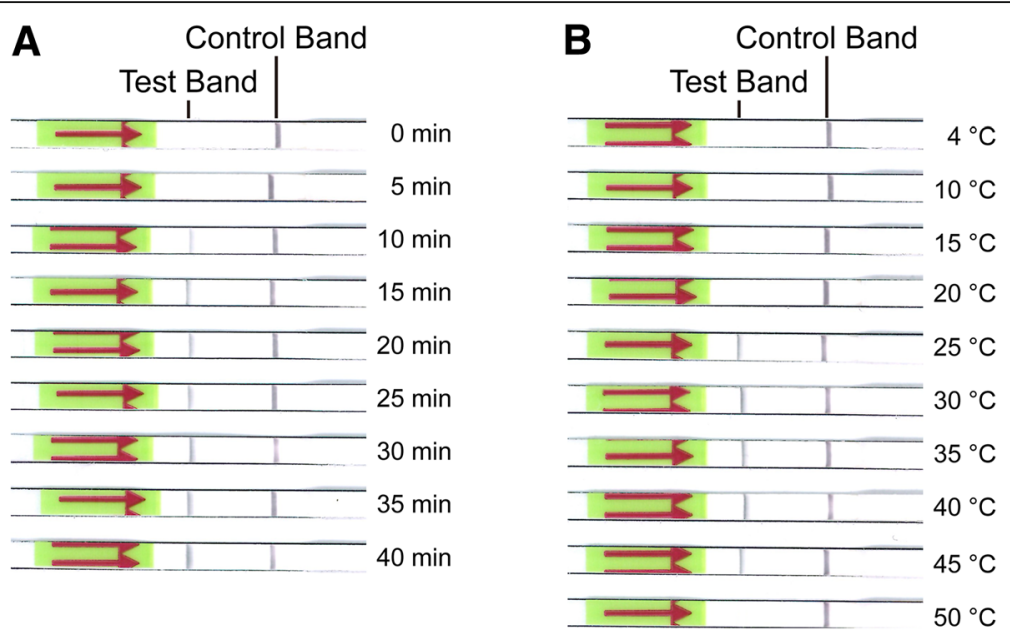

Fig. 3 Analysis of optimal amplification time and temperature. The amplification time (a) and temperature (b) were shown on the right. 0.64 pg of genomic DNA of C. neoformans var. grubii H99 (ATCC 208821) was used as templates. a amplification time. A clear test band appeared and became more solid as time extended to $10 \mathrm{~min}$ or more. $\mathbf{b}$ amplification temperature. An obvious test band could be seen over a wide range of temperature from 25 to $45^{\circ} \mathrm{C}$.

preliminary experiments show that 5 min is sufficient for displaying test signals $[20,25,29-32]$. In one word, the whole time of LF-RPA assay from start of template preparation to detection on strips is about $35 \mathrm{~min}$. Moreover, Fig. $3 \mathrm{~b}$ showed that the method could run well at a wide range of temperature from 25 to $45^{\circ} \mathrm{C}$, suggesting that running this system does not require additional special heating equipment [25]. Furthermore, there is no need for trained staff to interpret the results because the test results appeared as visible band can be easily read with naked eyes by untrained personnel, which saves labor costs and time $[25,29]$. To summarize, the LF-RPA assay presented here is a relatively ideal method for rapid and visual detection of Cryptococcus spp. especially in remote regions.

Subsequently, 114 clinical specimens were used to calculate the diagnostic parameters of the LF-RPA system. Almost perfect combination of primer-probe and high amplification efficiency are the basement and guarantee of high sensitivity. Relatively higher sensitivity indicates that the LF-RPA method might be useful for clinical preliminary screening of Cryptococcus spp.. However, high sensitivity might also lead to higher false positive rate [33, 34].
Of course these false positive specimens might also be cross-contaminated by other positive samples or polluted by laboratory environment although there are strict antipollution measures.

At first we thought that the relatively pure template would obviously affect the detection efficiency of the system. However, this was not the case. As amplification template, both cell lysates and genomic DNA produce similar experimental results (Fig. 4). It is clearly shown that the RPA system is robust and highly tolerant $[29,30,35]$.

There is still the undeniable fact that our LF-RPA system has many shortcomings. (1) The performance characteristics of our LF-RPA assay have not been established for plasma, serum, or whole blood other than cerebral spinal fluid. This will be one of our main research directions in the future. (2) Compared with other molecular detection methods, the current cost of the LF-RPA assay is relatively higher. As the yield increase, prices may decrease in the future. (3) Although the whole process of visual analysis is carried out in a dedicated class II biosafety cabinet, the possibility of cross contamination

Table 3 Estimation of diagnostic validity of LF-RPA assay with 114 CSF specimens

\begin{tabular}{|c|c|c|c|c|c|c|c|}
\hline & & \multicolumn{2}{|c|}{ Culture/India ink staining } & \multicolumn{4}{|c|}{ Performance characteristics (\%) } \\
\hline & & Positive & Negative & Se & $S p$ & PPV & NPV \\
\hline \multirow[t]{2}{*}{ LF-RPA } & Pos & 40 & 3 & $95.2^{\mathrm{a}}$ & $95.8^{\mathrm{b}}$ & $93.0^{c}$ & $97.2^{d}$ \\
\hline & Neg & 2 & 69 & & & & \\
\hline \multirow[t]{2}{*}{ CrAg Lateral Flow Assay } & Pos & 42 & 0 & $100^{e}$ & $100^{f}$ & 100 & 100 \\
\hline & Neg & 0 & 72 & & & & \\
\hline
\end{tabular}

Pos: positive; Neg: negative; Se: sensitivity; Sp: specificity; PPV: positive predictive value; NPV: negative predictive value; Cl: confidence interval.

${ }^{\text {a }}$ 95\% Cl: 83.84\%-99.42\%; ${ }^{\text {b } 95 \% ~ C l: ~ 88.30 \%-99.13 \% ; ~}{ }^{c} 95 \%$ Cl: 81.46\%-97.59\%; ${ }^{\text {d } 95 \% ~ C l: ~ 89.91 \%-99.26 \% ; ~}{ }^{\mathrm{e}} 95 \%$ Cl: $91.59 \%-100.00 \%$; ${ }^{\text {f }} 95 \%$ Cl: $95.01 \%-100.00 \%$. 


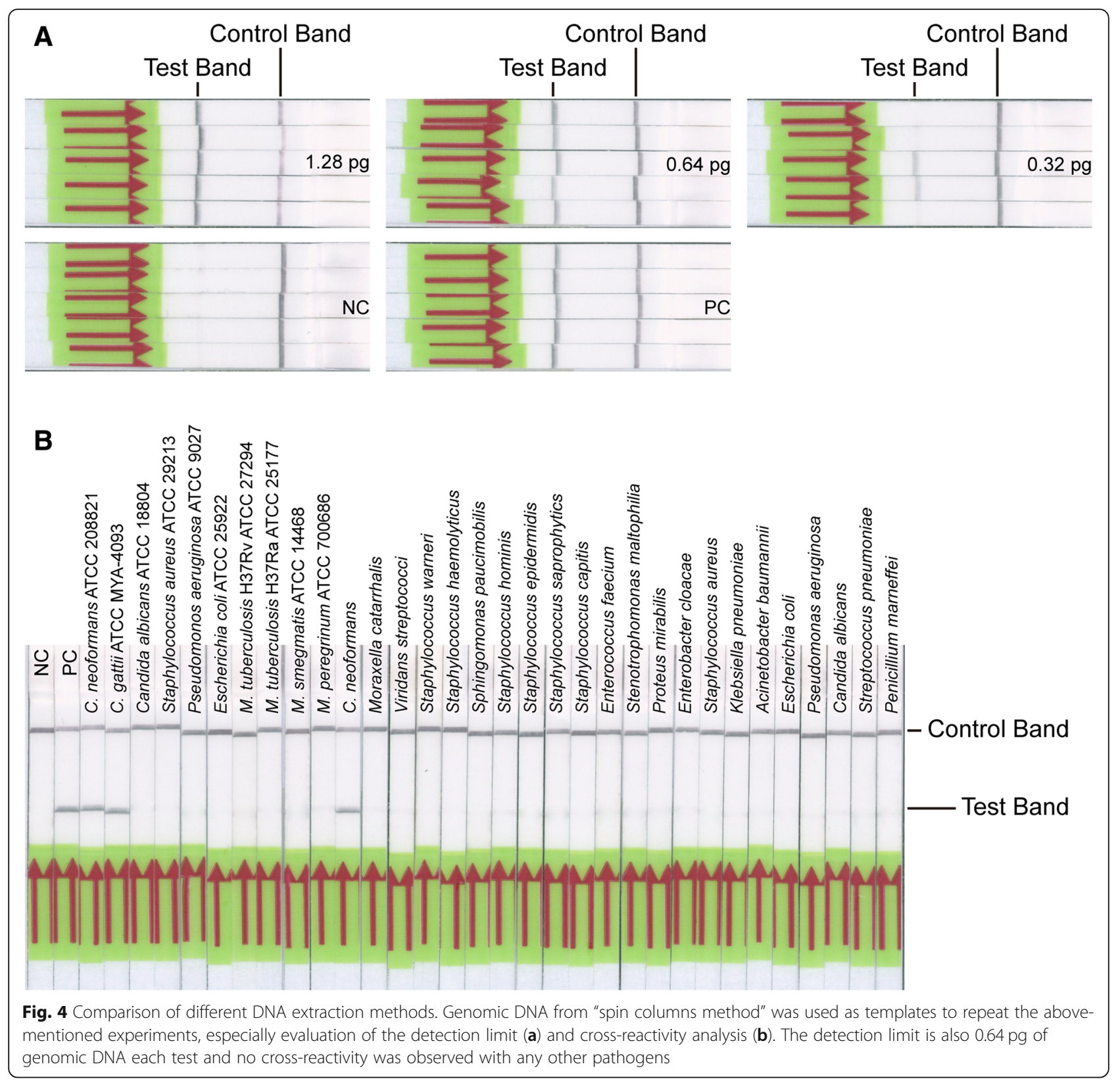

between samples is still high because of the abundant amplicons. A cross-contamination-proof cassette will be used to eliminate the need of opening the amplification tubes, thus minimizing the chance of contamination [36-38]. (4) Recently, duplex amplification detection of genomic DNA from Francisella tularensis and Yersinia pestis on only one nucleic-acid lateral flow strip has been reported [39]. It just confirms our ongoing research: duplex lateral flow assay for the simultaneous detection of $C$. neoformans and Canidia albicans. This is our another research direction. Although there are many methods for detecting pathogens based on RPA assays, there is still a long way before they are actually applied to clinical practice.

\section{Conclusions}

In conclusion, the LF-RPA system described here is shown to be a sensitive, specific, and robust method for the visible, rapid, and accurate detection of Cryptococcus spp. in cerebral spinal fluid and might be useful for clinical preliminary screening of cryptococcal meningitis.

\section{Abbreviations}

ATCC: American type culture collection; CM: Cryptococcal meningitis; CrAg: Cryptococcal antigen polysaccharide; CSF: Cerebral spinal fluid; 
ITS: Internal transcribed spacer; LF: Lateral flow; RPA: Recombinase polymerase amplification; SDA: Sabouraud dextrose agar

\section{Acknowledgments}

We would like to thank the staffs and directors of the two hospitals for their support, permission and assistance in samples collection and laboratory work.

\section{Funding}

This work was supported by the National Natural Science Foundation of China (81702087), Shenzhen Scientific and Technological Foundation (JCYJ20160427152933037, JCYJ20160427152241973), and Shenzhen Healthcare Research Project (201605010). The funders had no role in the design of the study and collection, analysis, and interpretation of data and in writing the manuscript.

\section{Availability of data and materials}

The dataset used and analyzed in this study is available from the corresponding author on reasonable request.

\section{Authors' contributions}

QM conceived and designed all the experiments and wrote the paper; QM and JY analyzed the data; JY, SY and HL performed the experiments and advised on primer-probe design; WS and HL performed the clinical culture and collected clinical isolates and CSF samples; NW, JZ and WS contributed materials, revised the manuscript, and provided leadership for all the work. All authors discussed the results, provided comments and approved the final version of the manuscript.

\section{Ethics approval and consent to participate}

Since above-mentioned clinical specimens were residual and discarded samples from routine clinical diagnosis test and it won't have any adverse effect on anyone, the ethics committee of Shenzhen Third People's Hospital agreed to waive the informed consent and passed the ethical review.

\section{Consent for publication}

Not applicable.

\section{Competing interests}

The authors have read and understood BMC Infectious Diseases policy on declaration of interests and declare that they have no competing interests.

\section{Publisher's Note}

Springer Nature remains neutral with regard to jurisdictional claims in published maps and institutional affiliations

Received: 3 August 2018 Accepted: 25 January 2019

Published online: 04 February 2019

References

1. Aderman CM, Gorovoy IR, Chao DL, Bloomer MM, Obeid A, Stewart JM. Cryptococcal choroiditis in advanced AIDS with clinicopathologic correlation. American journal of ophthalmology case reports. 2018;10:51-4

2. Williamson PR, Jarvis JN, Panackal AA, Fisher MC, Molloy SF, Loyse A Harrison TS. Cryptococcal meningitis: epidemiology, immunology, diagnosis and therapy. Nat Rev Neurol. 2017;13(1):13-24.

3. Ming DK, Harrison TS. Cryptococcal meningitis. Br J Hosp Med. 2017; 78(8):C125-7

4. Makadzange AT, McHugh G. New approaches to the diagnosis and treatment of cryptococcal meningitis. Semin Neurol. 2014:34(1):47-60.

5. Lin X, Heitman J. The biology of the Cryptococcus neoformans species complex. Annu Rev Microbiol. 2006:60:69-105.

6. Liu ZY, Wang GQ, Zhu LP, Lyu XJ, Zhang QQ, Yu YS, Zhou ZH, Liu YB, Cai $W P$, Li RY, et al. Expert consensus on the diagnosis and treatment of cryptococcal meningitis. Zhonghua nei ke za zhi. 2018;57(5):317-23.

7. Perfect JR, Bicanic T. Cryptococcosis diagnosis and treatment: what do we know now. Fungal Genet Biol. 2015;78:49-54.

8. Chammard TB, Temfack E, Lortholary O, Alanio A. Diagnostic and therapeutic strategies in cryptococcosis: impact on outcome. Memorias do Instituto Oswaldo Cruz. 2018;113(7):e180050.
9. Dromer F, Mathoulin-Pelissier S, Launay O, Lortholary O, French Cryptococcosis Study G. Determinants of disease presentation and outcome during cryptococcosis: the CryptoA/D study. PLoS Med. 2007;4(2):e21.

10. Arendrup MC, Bille J, Dannaoui E, Ruhnke M, Heussel CP, Kibbler C. ECIL-3 classical diagnostic procedures for the diagnosis of invasive fungal diseases in patients with leukaemia. Bone Marrow Transplant. 2012:47(8):1030-45.

11. Temfack E, Kouanfack C, Mossiang L, Loyse A, Fonkoua MC, Molloy SF, Koulla-Shiro S, Delaporte E, Dromer F, Harrison T, et al. Cryptococcal antigen screening in asymptomatic HIV-infected antiretroviral naive patients in Cameroon and evaluation of the new semi-quantitative Biosynex CryptoPS test. Front Microbiol. 2018:9:409.

12. Hansen J, Slechta ES, Gates-Hollingsworth MA, Neary B, Barker AP, Bauman S, Kozel TR, Hanson KE. Large-scale evaluation of the immuno-mycologics lateral flow and enzyme-linked immunoassays for detection of cryptococcal antigen in serum and cerebrospinal fluid. Clin Vaccine Immunol. 2013;20(1):52-5.

13. Rugemalila J, Maro VP, Kapanda G, Ndaro AJ, Jarvis JN. Cryptococcal antigen prevalence in HIV-infected Tanzanians: a cross-sectional study and evaluation of a point-of-care lateral flow assay. Tropical Med Int Health. 2013;18(9):1075-9.

14. Jitmuang A, Panackal AA, Williamson PR, Bennett JE, Dekker JP, Zelazny AM. Performance of the Cryptococcal antigen lateral flow assay in non-HIV-related Cryptococcosis. J Clin Microbiol. 2016;54(2):460-3.

15. Tintelnot K, Hagen F, Han CO, Seibold M, Rickerts V, Boekhout T. Pitfalls in serological diagnosis of Cryptococcus gattii infections. Med Mycol. 2015;53(8):874-9.

16. Piepenburg O, Williams CH, Stemple DL, Armes NA. DNA detection using recombination proteins. PLOS Biol. 2006:4(7):e204.

17. Hoff M. DNA amplification and detection made simple (relatively). PLoS Biol. 2006:4(7):e222.

18. Daher RK, Stewart G, Boissinot M, Bergeron MG. Recombinase polymerase amplification for diagnostic applications. Clin Chem. 2016;62(7):947-58.

19. Clancy E, Higgins O, Forrest MS, Boo TW, Cormican M, Barry T, Piepenburg $\mathrm{O}$, Smith TJ. Development of a rapid recombinase polymerase amplification assay for the detection of Streptococcus pneumoniae in whole blood. BMC Infect Dis. 2015:15:481.

20. Ma Q, Liu H, Ye F, Xiang G, Shan W, Xing W. Rapid and visual detection of mycobacterium tuberculosis complex using recombinase polymerase amplification combined with lateral flow strips. Mol Cell Probes. 2017;36:43-9.

21. Zhao G, Wang H, Hou P, He C, He H. Rapid visual detection of Mycobacterium avium subsp. paratuberculosis by recombinase polymerase amplification combined with a lateral flow dipstick. J Vet Sci. 2018:19(2):242-50

22. Weiss JB. DNA probes and PCR for diagnosis of parasitic infections. Clin Microbiol Rev 1995:8(1):113-30.

23. Davila AM, Momen H. Internal-transcribed-spacer (ITS) sequences used to explore phylogenetic relationships within Leishmania. Ann Trop Med Parasitol. 2000;94(6):651-4

24. Som I, Azam A, Bhattacharya A, Bhattacharya S. Inter- and intra-strain variation in the $5.8 \mathrm{~S}$ ribosomal RNA and internal transcribed spacer sequences of Entamoeba histolytica and comparison with Entamoeba dispar, Entamoeba moshkovskii and Entamoeba invadens. Int J Parasitol. 2000;30(6):723-8.

25. Soliman H, Kumar G, El-Matbouli M. Recombinase polymerase amplification assay combined with a lateral flow dipstick for rapid detection of Tetracapsuloides bryosalmonae, the causative agent of proliferative kidney disease in salmonids. Parasit Vectors. 2018:11(1):234.

26. Mohammadi A, Hashemi SM, Abtahi SH, Lajevardi SM, Kianipour S, Mohammadi R. An investigation on non-invasive fungal sinusitis; molecular identification of etiologic agents. Journal of research in medical sciences : the official journal of Isfahan University of Medical Sciences. 2017;22:67.

27. Guo Y, Zhou Y, Wang C, Zhu L, Wang S, Li Q, Jiang G, Zhao B, Huang H, Yu $\mathrm{H}$, et al. Rapid, accurate determination of multidrug resistance in $M$ Tuberculosis isolates and sputum using a biochip system. Int J Tuberc Lung Dis. 2009;13(7):914-20.

28. GAd S, Bernardi TL, Schaker PDC, Menegotto M, Valente P. Rapid yeast DNA extraction by boiling and freeze-thawing without using chemical reagents and DNA purification. Braz Arch Biol Technol. 2012:55(2):319-27.

29. Sun K, Xing W, Yu X, Fu W, Wang Y, Zou M, Luo Z, Xu D. Recombinase polymerase amplification combined with a lateral flow dipstick for rapid and visual detection of Schistosoma japonicum. Parasit Vectors. 2016;9:476. 
30. Kersting S, Rausch V, Bier FF, von Nickisch-Rosenegk M. Rapid detection of plasmodium falciparum with isothermal recombinase polymerase amplification and lateral flow analysis. Malar J. 2014;13:99.

31. Du XJ, Zang YX, Liu HB, Li P, Wang S. Recombinase polymerase amplification combined with lateral flow strip for listeria monocytogenes detection in food. J Food Sci. 2018;83(4):1041-7.

32. Qi Y, Yin Q, Shao Y, Cao M, Li S, Chen H, Shen W, Rao J, Li J, Li X, et al. Development of a rapid and visual nucleotide detection method for a Chinese epidemic strain of Orientia tsutsugamushi based on recombinase polymerase amplification assay and lateral flow test. International journal of infectious diseases : IJID : official publication of the International Society for Infectious Diseases. 2018;70:42-50.

33. Altman DG, Bland JM. Diagnostic tests. 1: sensitivity and specificity. Bmj. 1994;308(6943):1552.

34. Simon R. Sensitivity, specificity, PPV, and NPV for predictive biomarkers. J Natl Cancer Inst. 2015;107(8).

35. Rohrman B, Richards-Kortum R. Inhibition of recombinase polymerase amplification by background DNA: a lateral flow-based method for enriching target DNA. Anal Chem. 2015;87(3):1963-7.

36. Chao CC, Belinskaya T, Zhang Z, Ching WM. Development of recombinase polymerase amplification assays for detection of Orientia tsutsugamushi or rickettsia typhi. PLoS Negl Trop Dis. 2015:9(7):e0003884.

37. Gou H, Deng J, Wang J, Pei J, Liu W, Zhao M, Chen J. Rapid and sensitive detection of porcine epidemic diarrhea virus by reverse transcription loop-mediated isothermal amplification combined with a vertical flow visualization strip. Mol Cell Probes. 2015;29(1):48-53.

38. Gou H, Deng J, Pei J, Wang J, Liu W, Zhao M, Chen J. Rapid and sensitive detection of type II porcine reproductive and respiratory syndrome virus by reverse transcription loop-mediated isothermal amplification combined with a vertical flow visualization strip. J Virol Methods. 2014;209:86-94.

39. Jauset-Rubio M, Tomaso H, El-Shahawi MS, Bashammakh AS, Al-Youbi AO, O'Sullivan CK. Duplex lateral flow assay for the simultaneous detection of Yersinia pestis and Francisella tularensis. Anal Chem. 2018.

Ready to submit your research? Choose BMC and benefit from:

- fast, convenient online submission

- thorough peer review by experienced researchers in your field

- rapid publication on acceptance

- support for research data, including large and complex data types

- gold Open Access which fosters wider collaboration and increased citations

- maximum visibility for your research: over $100 \mathrm{M}$ website views per year

At $\mathrm{BMC}$, research is always in progress.

Learn more biomedcentral.com/submissions 